\title{
Bending-Shear Interaction Domains for Externally Prestressed Concrete Girders
}

\author{
Antonino Recupero ${ }^{1}$ and Michele Fabio Granata ${ }^{2}$ \\ ${ }^{1}$ Università di Messina, DICIEAMA, C/da Di Dio, 98166 Messina, Italy \\ ${ }^{2}$ Università di Palermo, DICAM, Viale delle Scienze, 90128 Palermo, Italy \\ Correspondence should be addressed to Michele Fabio Granata; michelefabio.granata@unipa.it
}

Received 4 July 2013; Revised 15 September 2013; Accepted 1 October 2013

Academic Editor: Andreas Kappos

Copyright (C) 2013 A. Recupero and M. F. Granata. This is an open access article distributed under the Creative Commons Attribution License, which permits unrestricted use, distribution, and reproduction in any medium, provided the original work is properly cited.

\begin{abstract}
In prestressed concrete structures, the evaluation of the safety level is generally carried out by separating the bending moment strength and the shear force capacity. Actually interaction between bending moment $(M)$ and shear force $(V)$ can have significant consequences on evaluations in service life, especially when the ultimate limit state (ULS) is considered. In this paper, the $M-V$ interaction is addressed for prestressed concrete girders, in the cases of both bonded and unbonded prestressing tendons. It can be demonstrated, by drawing the interaction domains $(M-V)$, that a significant reduction of the safety level has to be considered when shear force is evaluated together with bending moment on the ULS of the cross-section, especially for external prestressing in concrete T-shaped or box sections of bridge girders. Interaction domains allow designers to evaluate and optimize reinforcement ratios, geometric properties of the beam, and effects of shear on the ultimate state. An analytical model, based on the stress field theory, is developed and proposed in this paper. A numerical example is developed and interaction domains are given for an example of a box section with variation in reinforcement ratio and tendon slope. A validation of the presented model is given, by comparing experimental data in the literature with results found using the proposed analytical approach.
\end{abstract}

\section{Introduction}

In the last few decades many concrete structures with external prestressing have appeared, especially in the field of small and medium span bridge girders. Unbonded prestressing is a technology which is rapidly spreading for new constructions and for the rehabilitation and retrofitting of existing ones [1, 2]; many interventions with external prestressing have been carried out for strengthening existing deteriorated bridges [3] and this technique provides an efficient and cheap solution for a wide range of bridge typologies. On the other hand, suitable conceptual tools which clarify the behaviour of these structures have not been consolidated, especially for ultimate behaviour under shear and shear-bending moment interaction, although valuable contributions have been made in this direction [4]. Moreover, for reinforced concrete (RC) structures it is known that the actual behaviour near collapse is greatly influenced by the interaction between shear, bending moment, and axial force [5, 6]. Bairan Garcia and Marì
Bernat [7-9] studied the shear-bending-torsion interaction in structural concrete members by a nonlinear approach and a coupled model for section analysis subjected to general 3D loading, while Rahal [10] studied the bending-torsion interaction using a simplified method. In the last fifty years, theoretical and experimental investigations [11] have clarified the principal aspects of shear failure. In the literature, valuable contributions can be recognized for structures with ordinary unprestressed reinforcing steel, about the shear-bending moment-axial force interaction [12, 13]. Investigations and studies are available for beams with rectangular, T-, I-shaped, box, and circular cross-sections $[5,14]$.

Models presented in the literature can be divided on the basis of the two main philosophies established for the technical approach to this topic:

(i) the first is strictly inspired by experimental evidence and tests on reinforced concrete (RC) elements and it tries to give practical formulas, directly derived from experimental data; 
(ii) the second provides a more general model that takes into account the influence of internal force interactions, on the base of the so-called "stress fields" theory, as proposed by Braestrup et al. [18] and now inserted in recent codes and recommendations $[19,20]$.

Recent developments on shear strength evaluation of RC structures with the "stress field theory" are available in the literature [21-24].

The influence of the actual behaviour of prestressed concrete girders is particularly important when evaluations on service and ultimate limit states of bridges have to be carried out, both in construction stages and during service life.

Bonded and unbonded prestressing are nowadays prevalent in box concrete girders of segmental bridges built by cantilevering $[25,26]$, or in incrementally launched bridges $[27,28]$. For girder bridges the influence of the bendingshear interaction on the final safety level of these structures can be significant, added to the modifications of the stress state given by time-dependent phenomena like creep and shrinkage $[25,29]$. Moreover, the strong interaction between bending, shear, and axial force always has to be evaluated in arch bridge structures, especially when they are built with complex construction sequences, by suspended cantilevers [30] or lattice cantilevers [31].

In this paper the bending-shear $(M-V)$ interaction is considered for prestressed concrete girders, in the case of both bonded and unbonded prestressing tendons. The aim of the study is to supply a suitable tool for drawing the interaction domains and for fast verification of the structural safety level by considering the interaction between bending and shear. Moreover, the proposed approach allows designer to optimize the amount of longitudinal and transverse reinforcement in bonded and unbonded prestressed girders.

In common practice in fact the evaluation of the safety level is carried out separately and there is lack of knowledge about the actual behaviour of external unbonded prestressing, especially regarding the influence of shear on the beam failure. It is difficult to find valuable experimental contributions in this field because the majority of studies are generally focused on bending and the specimens used in experimental tests are too slender to show a shear collapse. A few interesting analytical values and experimental tests on beams with unprestressed $[15,16]$ and prestressed reinforcement [17] have been recognized in the literature, which could be useful for the validation of the present study.

An analytical model, based on the stress field theory, is developed and proposed here, which can be helpful for understanding the actual behaviour of externally prestressed concrete girders, by comparing it to structures with bonded tendons. A numerical example is developed and interaction domains are given for an example of common box sections. The model provides a unified approach for RC and PC elements with bonded or unbonded tendons. The model has already been validated for RC structures [14]. In this study the validation is given for prestressed sections, by comparing experimental data in the literature with the results found using the proposed model.
The results show a significant reduction of the safety level when shear force is evaluated together with bending moment on the ultimate limit state of the cross-section, especially for external prestressing in concrete T-shaped or box sections of bridge girders. The fact is that unbonded tendons contribute to a marked decrease in ductility near collapse, as shown by experimental tests. By comparing literature data with analytical theoretical results, good agreement is found. In particular, the role of compressive strength value inserted in the model and suggested by international codes as well as the effective shear-resistant web area is investigated and underlined. Outcomes of domains for bonded and unbonded prestressing are discussed with variation in reinforcement ratio and tendon slope.

Finally, the use of interaction domains is encouraged as a convenient graphic design-verification tool, able to show the interaction effects between internal forces.

\section{The Proposed Analytical Model}

The proposed model is a generalization of a previous one formulated for structural elements with unprestressed reinforcement [14].

The actual distribution of stress fields in concrete members with high compressive stresses is strictly linked to the state of deformations, so compatibility equations would be implemented in a more complete and complex model that may not be reliable from the computational point of view. A perfectly plastic approach, instead, introduces a suitable simplification, by considering a physical model in terms of equilibrium equations only. An approach of this kind could be more useful for designers than complex nonlinear analyses with finite elements. The perfectly plastic approach can be implemented by assuming the hypothesis that different portions of cross-section members are mainly required to face different values of stress due to internal forces: some are required to carry axial stress and others shear stress.

Nevertheless, it is less difficult to evaluate the ultimate strength of structural elements when the following hypotheses are considered

(1) Near failure, the behaviour of the beam can be interpreted through an extension of classical strut and tie models (as in the Ritter-Mörsch truss). In this idealized complex multiple truss structure, the stirrups, longitudinal reinforcements, tension chord and prestressing tendons constitute elements in tension; the compressed elements are instead given by concrete of the opposite chord, with the relative compressed ordinary reinforcement, and by the web concrete stress fields.

(2) The uniform web stress field is inclined by an angle $\theta$ with respect to the longitudinal direction, which may differ from the classical value of 45 degrees.

(3) Longitudinal and transverse reinforcements are subjected only to axial forces (the Dowel effect is negligible) and their action can be described by distributed stress fields, supposing them to be uniformly distributed and densely spaced. 
(4) The constitutive laws of the materials used in the proposed model are based on the plasticity theory.

As proposed in a previous study [14] the static theorem of the plasticity theory is applied, which gives the so-called "lower bound solution" [32].

With reference to the generic beam segment in Figure 1, assuming the beam section is T-, I-, or box shaped, a cut is made at the abscissa $x$, with the parallel direction to the field of the concrete web stress. The related equilibrium equations are

$$
\begin{aligned}
& V^{*}-q \cdot x-\frac{\sigma_{t w}}{f_{s y d}} \omega_{t w} \cdot f_{c d 2} \cdot z_{3} \cdot b_{w}(\operatorname{ctg} \theta+\operatorname{ctg} \alpha) \sin ^{2} \alpha \\
& -\sum\left(A_{p} \sigma_{p} \sin \varepsilon\right)_{i}=0 \text {, } \\
& M^{*}+\frac{q x^{2}}{2}-C^{\prime \prime} \bar{z}+\frac{\sigma_{t w}}{f_{s y d}} \omega_{t w} \cdot f_{c d 2} \cdot z_{3} \\
& \cdot b_{w}(\operatorname{ctg} \theta+\operatorname{ctg} \alpha) \sin ^{2} \alpha \cdot x+\frac{\sigma_{t w}}{f_{s y d}} \omega_{t w} \cdot f_{c d 2} \cdot z_{3} \\
& \cdot b_{w}(\operatorname{ctg} \theta+\operatorname{ctg} \alpha) \sin \alpha \cos \alpha \cdot\left(\bar{z}_{2}+\frac{z_{3}}{2}\right) \\
& +\frac{\sigma_{l w}}{f_{s y d}} \omega_{l w} \cdot f_{c d 2} \cdot z_{3} \\
& \cdot b_{w} \cdot\left(\bar{z}_{2}+\frac{z_{3}}{2}\right)+\sum\left(A_{p} \sigma_{p} \sin \varepsilon\right)_{i} \cdot x \\
& +\sum\left(A_{p} \sigma_{p} \cos \varepsilon\left(\bar{z}+t_{1}-y_{p}\right)\right)_{i}=0 \\
& M^{*}+\frac{q x^{2}}{2}-T^{\prime} \cdot \bar{z}+\frac{\sigma_{t w}}{f_{s y d}} \omega_{t w} \cdot f_{c d 2} \cdot z_{3} \\
& \cdot b_{w}(\operatorname{ctg} \theta+\operatorname{ctg} \alpha) \sin ^{2} \alpha \cdot x \\
& -\frac{\sigma_{t w}}{f_{s y d}} \omega_{t w} \cdot f_{c d 2} \cdot z_{3} \\
& \cdot b_{w}(\operatorname{ctg} \theta+\operatorname{ctg} \alpha) \sin \alpha \cos \alpha \cdot\left(\bar{z}_{1}+\frac{z_{3}}{2}\right) \\
& -\frac{\sigma_{l w}}{f_{s y d}} \omega_{l w} \cdot f_{c d 2} \cdot z_{3} \cdot b_{w} \cdot\left(\bar{z}_{1}+\frac{z_{3}}{2}\right) \\
& +\sum\left(A_{p} \sigma_{p} \sin \varepsilon\right)_{i} \cdot x \\
& -\sum\left(A_{p} \sigma_{p} \cos \varepsilon\left(y_{p}-t_{1}\right)\right)_{i}=0 \text {. }
\end{aligned}
$$

In the previous equations the meanings of the symbols are the following. $\sigma_{t w}$ is the stress of transverse reinforcement (i.e. the stress field of stirrups inclined by the angle $\alpha$, which is uniformly distributed along the crack and is statically equivalent to the tensile resultant force of transverse reinforcements); $\sigma_{l w}$ is the stress field related to longitudinal reinforcement; $f_{s y d}$ is the strength of the ordinary steel of the reinforcements; $f_{c d 2}$ is the reduced compressive strength of the concrete for transverse loads; $b_{w}$ is the web thickness; $A_{p i}, \sigma_{p i}$, and $\varepsilon_{i}$ are the area, axial stress, and slope of the $i$ th prestressing tendon. Other quantities are shown in Figure 1: $\bar{z}_{1}$ is the distance from the point of application of the compressive resultant to the lowest compression fibre, $\bar{z}_{2}$ is the distance from the point of application of the tensile resultant to the highest tension fibre, and $z_{3}$ the depth of the web shear-resistant area. $\bar{z}_{1}, \bar{z}_{2}, z_{3}, \sigma_{l w}$ and $\sigma_{t w}$ are all variables of the problem, varying inside ranges determined by geometric and mechanical conditions, which will be explained in the following sections.

Introducing the expression of shear at the abscissa $x$, the following relation can be obtained:

$$
\begin{aligned}
V_{s d}(x)= & \frac{\sigma_{t w}}{f_{s y d}} \omega_{t w} \cdot f_{c d 2} \cdot z_{3} \cdot b_{w} \\
& \cdot(\operatorname{ctg} \theta+\operatorname{ctg} \alpha) \sin ^{2} \alpha+\sum\left(A_{p} \cdot \sigma_{p} \cdot \sin \varepsilon\right)_{i}
\end{aligned}
$$

In (4) the contribution of prestressing to the shear force can be recognized in the last term of the equation. By introducing this relation into (3) and (2) and recalling the expression of the bending moment at the abscissa $x$, the following relations are obtained, which give the resultant forces in the compression and tension chords of the beam:

$$
\begin{aligned}
C^{\prime \prime} \bar{z}= & M_{s d}+V_{s d} \operatorname{ctg} \alpha\left(\bar{z}_{2}+\frac{z_{3}}{2}\right) \\
& -\sum\left[A _ { p } \sigma _ { p } \operatorname { s i n } \varepsilon \cdot \left(\operatorname{ctg} \alpha \cdot\left(\bar{z}_{2}+\frac{z_{3}}{2}\right)\right.\right. \\
& \left.\left.-\operatorname{ctg} \varepsilon \cdot\left(\bar{z}+t_{1}-y_{p}\right)\right)\right]_{i} \\
& +\frac{\sigma_{l w}}{f_{s y d}} \omega_{l w} \cdot f_{c d 2} \cdot z_{3} \cdot b_{w} \cdot\left(\bar{z}_{2}+\frac{z_{3}}{2}\right), \\
T^{\prime} \cdot \bar{z}= & M_{s d}-V_{s d} \cdot \operatorname{ctg} \alpha \cdot\left(\bar{z}_{1}+\frac{z_{3}}{2}\right) \\
& +\sum\left[A _ { p } \sigma _ { p } \operatorname { s i n } \varepsilon \left(\operatorname{ctg} \alpha \cdot\left(\bar{z}_{1}+\frac{z_{3}}{2}\right)\right.\right. \\
& -\frac{\sigma_{l w}}{f_{s y d}} \omega_{l w} \cdot f_{c d 2} \cdot z_{3} \cdot b_{w} \cdot\left(\bar{z}_{1}+\frac{z_{3}}{2}\right) .
\end{aligned}
$$

By operating on the same beam segment, now with a cut at the abscissa $x$ that is parallel to the field of the web 


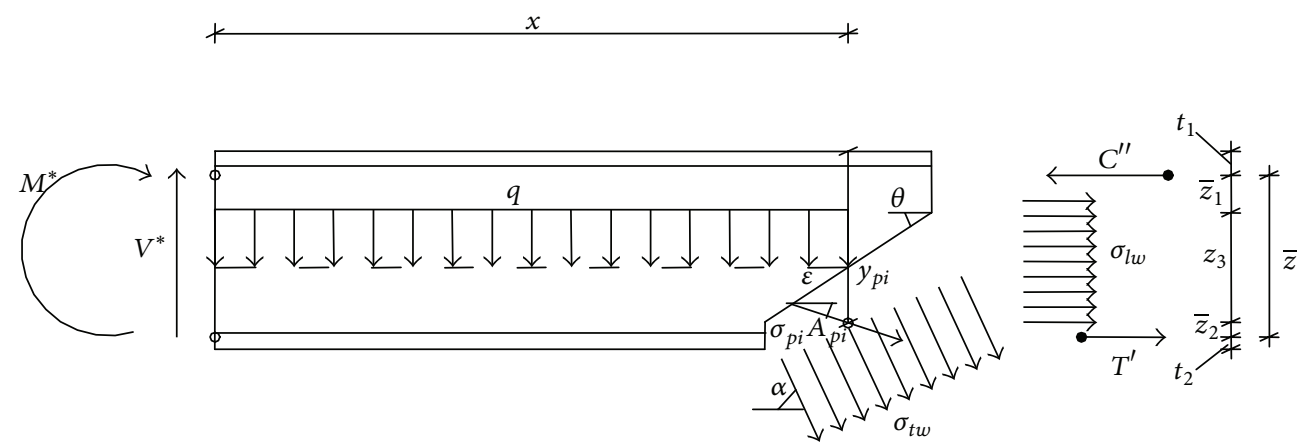

FIGURE 1: Beam segment with a cut parallel to the stress field of the web concrete.

stresses, related to the transverse reinforcements (Figure 2), the following expressions can be obtained:

$$
\begin{aligned}
& V^{*}-q \cdot x-\sigma_{c w} \cdot z_{3} \cdot b_{w} \\
& \cdot(\operatorname{ctg} \theta+\operatorname{ctg} \alpha) \sin ^{2} \theta-\sum\left(A_{p} \sigma_{p} \sin \varepsilon\right)_{i}=0 \\
& M^{*}+\frac{q x^{2}}{2}-C^{\prime} \bar{z}+\sigma_{c w} \cdot z_{3} \cdot b_{w}(\operatorname{ctg} \theta+\operatorname{ctg} \alpha) \sin ^{2} \theta \cdot x \\
& \quad-\sigma_{c w} \cdot z_{3} \cdot b_{w}(\operatorname{ctg} \theta+\operatorname{ctg} \alpha) \sin \theta \cos \theta \cdot\left(\bar{z}_{2}+\frac{z_{3}}{2}\right) \\
& +\frac{\sigma_{l w}}{f_{s y d}} \omega_{l w} \cdot f_{c d 2} \cdot z_{3} \cdot b_{w} \cdot\left(\bar{z}_{2}+\frac{z_{3}}{2}\right) \\
& +\sum\left(A_{p} \sigma_{p} \sin \varepsilon\right)_{i} \cdot x \\
& +\sum\left(A_{p} \sigma_{p} \cos \varepsilon\left(\bar{z}+t_{1}-y_{p}\right)\right)_{i}=0 \\
& M^{*}+\frac{q x^{2}}{2}-T^{\prime \prime} \cdot \bar{z}+\sigma_{c w} \cdot z_{3} \cdot b_{w}(\operatorname{ctg} \theta+\operatorname{ctg} \alpha) \sin ^{2} \theta \cdot x \\
& +\sigma_{c w} \cdot z_{3} \cdot b_{w}(\operatorname{ctg} \theta+\operatorname{ctg} \alpha) \sin \theta \cos \theta \cdot\left(\bar{z}_{1}+\frac{z_{3}}{2}\right) \\
& +\frac{\sigma_{l w}}{f_{s y d}} \omega_{l w} \cdot f_{c d 2} \cdot z_{3} \cdot b_{w} \cdot\left(\bar{z}_{1}+\frac{z_{3}}{2}\right) \\
& +\sum\left(A_{p} \sigma_{p} \sin \varepsilon\right)_{i} \cdot x-\sum\left(A_{p} \sigma_{p} \cos \varepsilon\left(y_{p}-t_{1}\right)\right)_{i}=0
\end{aligned}
$$

$\sigma_{c w}$ being the value of the compressive stress in the concrete (inclined by the angle $\theta$ ), while $V^{*}$ and $M^{*}$ are the values of shear and bending moment at the initial beam section and $\omega_{t w}$ the mechanical percentage of transverse reinforcement.

Introducing the expression of shear at the abscissa $x$, the following relation can be obtained:

$$
\begin{aligned}
V_{s d}(x)= & \sigma_{c w} \cdot z_{3} \cdot b_{w} \cdot(\operatorname{ctg} \theta+\operatorname{ctg} \alpha) \sin ^{2} \theta \\
& +\sum\left(A_{p} \cdot \sigma_{p} \cdot \sin \varepsilon\right)_{i} .
\end{aligned}
$$

In (9) the contribution that the prestressing steel makes to the shear force can be recognized in the last term of the equation. By introducing this relation into (8) and (7) and recalling the expression of bending moment at the abscissa $x$, the following relations are obtained:

$$
\begin{aligned}
& C^{\prime} \bar{z}=M_{s d}-V_{s d} \operatorname{ctg} \theta\left(\bar{z}_{2}+\frac{z_{3}}{2}\right) \\
& +\sum\left[A _ { p } \sigma _ { p } \operatorname { s i n } \varepsilon \cdot \left(\operatorname{ctg} \theta \cdot\left(\bar{z}_{2}+\frac{z_{3}}{2}\right)\right.\right. \\
& \left.\left.+\operatorname{ctg} \varepsilon \cdot\left(\bar{z}+t_{1}-y_{p}\right)\right)\right]_{i} \\
& +\frac{\sigma_{l w}}{f_{s y d}} \omega_{l w} \cdot f_{c d 2} \cdot z_{3} \cdot b_{w} \cdot\left(\bar{z}_{2}+\frac{z_{3}}{2}\right), \\
& T^{\prime \prime} \cdot \bar{z}=M_{s d}+V_{s d} \cdot \operatorname{ctg} \theta \cdot\left(\bar{z}_{1}+\frac{z_{3}}{2}\right) \\
& -\sum\left[A _ { p } \sigma _ { p } \operatorname { s i n } \varepsilon \cdot \left(\operatorname{ctg} \theta \cdot\left(\bar{z}_{1}+\frac{z_{3}}{2}\right)\right.\right. \\
& \left.\left.-\operatorname{ctg} \varepsilon \cdot\left(y_{p}-t_{1}\right)\right)\right]_{i} \\
& -\frac{\sigma_{l w}}{f_{s y d}} \omega_{l w} \cdot f_{c d 2} \cdot z_{3} \cdot b_{w} \cdot\left(\bar{z}_{1}+\frac{z_{3}}{2}\right) .
\end{aligned}
$$

In order to obtain expressions which give the resultant force in the compression and tension chords of the beam, the values found in (5), (10) must be combined through the following further relations:

$$
\begin{aligned}
& C(x)=\frac{C^{\prime} \operatorname{ctg} \theta+C^{\prime \prime} \operatorname{ctg} \alpha}{\operatorname{ctg} \alpha+\operatorname{ctg} \theta}, \\
& T(x)=\frac{T^{\prime} \operatorname{ctg} \alpha+T^{\prime \prime} \operatorname{ctg} \theta}{\operatorname{ctg} \alpha+\operatorname{ctg} \theta},
\end{aligned}
$$




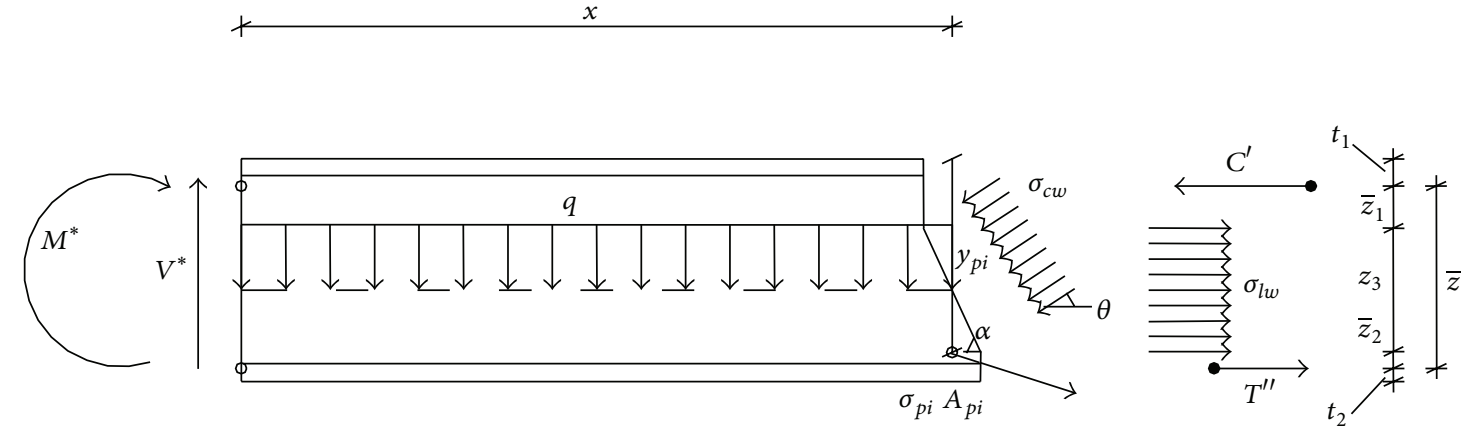

FIGURE 2: Beam segment with a cut parallel to the stirrups.

giving the fundamental expressions which supply the compression and tension resultants in the upper and lower chords of the beam:

$$
\begin{aligned}
C(x)= & \frac{M_{s d}+\sum\left[A_{p} \sigma_{p} \cos \varepsilon \cdot\left(\bar{z}+t_{1}-y_{p}\right)\right]_{i}}{\bar{z}} \\
- & {\left[\left(V_{s d}-\sum\left(A_{p} \sigma_{p} \sin \varepsilon\right)_{i}\right) \cdot(\operatorname{ctg} \theta-\operatorname{ctg} \alpha)\right.} \\
T(x)= & \left.-\frac{\sigma_{l w}}{f_{s y d}} \omega_{l w} \cdot f_{c d 2} \cdot z_{3} \cdot b_{w}\right] \cdot\left(\frac{2 \bar{z}_{2}+z_{3}}{2 \bar{z}}\right), \\
+ & +\left({ }_{s d}-\sum\left(A_{p} \sigma_{p} \cos \varepsilon \cdot\left(t_{1}-y_{p}\right)\right]_{i}\right. \\
\bar{z} & \left.\sin \varepsilon)_{i}\right) \cdot(\operatorname{ctg} \theta-\operatorname{ctg} \alpha) \\
& \left.-\frac{\sigma_{l w}}{f_{s y d}} \omega_{l w} \cdot f_{c d 2} \cdot z_{3} \cdot b_{w}\right] \cdot\left(\frac{2 \bar{z}_{1}+z_{3}}{2 \bar{z}}\right) .
\end{aligned}
$$

In the common case of prestressed beam with vertical stirrups $\left(\alpha=90^{\circ}\right),(4)$ and (9) can be simplified:

$$
\begin{gathered}
V_{s d}(x)=\frac{\sigma_{t w}}{f_{s y d}} \omega_{t w} \cdot f_{c d 2} \cdot z_{3} \cdot b_{w} \cdot \operatorname{ctg} \theta \\
+\sum\left(A_{p} \cdot \sigma_{p} \cdot \sin \varepsilon\right)_{i}, \\
V_{s d}(x)=\sigma_{c w} \cdot z_{3} \cdot b_{w} \cdot \cos \theta \sin \theta+\sum\left(A_{p} \cdot \sigma_{p} \cdot \sin \varepsilon\right)_{i}
\end{gathered}
$$

and consequently relations (12) become

$$
\begin{aligned}
C(x)= & \frac{M_{s d}+\sum\left[A_{p} \sigma_{p} \cos \varepsilon \cdot\left(\bar{z}+t_{1}-y_{p}\right)\right]_{i}}{\bar{z}} \\
& -\left[\left(V_{s d}-\sum\left(A_{p} \sigma_{p} \sin \varepsilon\right)_{i}\right)\right. \\
& \left.\cdot \operatorname{ctg} \theta-\frac{\sigma_{l w}}{f_{s y d}} \omega_{l w} \cdot f_{c d 2} \cdot z_{3} \cdot b_{w}\right] \cdot\left(\frac{2 \bar{z}_{2}+z_{3}}{2 \bar{z}}\right), \\
T(x)= & \frac{M_{s d}+\sum\left[A_{p} \sigma_{p} \cos \varepsilon \cdot\left(t_{1}-y_{p}\right)\right]_{i}}{\bar{z}} \\
& +\left[\left(V_{s d}-\sum\left(A_{p} \sigma_{p} \sin \varepsilon\right)_{i}\right)\right. \\
& \left.\cdot \operatorname{ctg} \theta-\frac{\sigma_{l w}}{f_{s y d}} \omega_{l w} \cdot f_{c d 2} \cdot z_{3} \cdot b_{w}\right] \cdot\left(\frac{2 \bar{z}_{1}+z_{3}}{2 \bar{z}}\right) .
\end{aligned}
$$

In order to evaluate the reinforcement of the upper and bottom flanges, the equivalence of the two compressive and tensile stress systems is imposed (Figure 3). For this condition the moment computed with respect to point $F_{2}$ allows one to find the expression in terms of total force of the upper reinforcement $S_{f 1}$, while the moment computed with respect to point $F_{1}$ allows one to find the expression in terms of total force of the bottom reinforcement $S_{f_{2}}$ :

$$
\begin{aligned}
S_{f 1}= & -B_{1} \cdot d_{1} \cdot \sigma_{f 1}+\frac{T(x) \cdot\left(2 t_{2}-d_{2}\right)-C(x) \cdot\left(2 H-d_{1}-2 t_{1}\right)}{2 H-d_{1}-d_{2}} \\
& -\frac{b_{w} \cdot\left[\sigma_{w 1} \cdot z_{1} \cdot\left(2 H-2 d_{1}-d_{2}-z_{1}\right)+\sigma_{w 2} \cdot z_{2} \cdot\left(d_{2}+z_{2}\right)\right]}{2 H-d_{1}-d_{2}}, \\
S_{f 2}= & -B_{2} \cdot d_{2} \cdot \sigma_{f 2}+\frac{T(x) \cdot\left(2 H-d_{1}-2 t_{2}\right)-C(x) \cdot\left(2 t_{1}-d_{1}\right)}{2 H-d_{1}-d_{2}} \\
& -\frac{b_{w} \cdot\left[\sigma_{w 1} \cdot z_{1} \cdot\left(d_{1}+z_{1}\right)+\sigma_{w 2} \cdot z_{2} \cdot\left(2 H-2 d_{2}-d_{1}-z_{2}\right)\right]}{2 H-d_{1}-d_{2}},
\end{aligned}
$$


where $B_{1}$ and $B_{2}, d_{1}$, and $d_{2}$ are the width and height of the flanges while the other geometric quantities are shown in Figure 3.

The minimum values of the reinforcement in the upper and bottom flanges are

$$
\begin{aligned}
& A_{f 1}=\frac{\left|S_{f 1}\right|}{f_{s y d}}, \\
& A_{f 2}=\frac{\left|S_{f 2}\right|}{f_{s y d}} .
\end{aligned}
$$

The reinforcement ratio $r=A_{f 1} / A_{f 2}=\left|S_{f 1}\right| /\left|S_{f 2}\right|$ is assigned by the designer and remains unchanged, so by calculating the ratio between the forces in the top and bottom reinforcements, the geometric reinforcement ratio is calculated too and it can be compared with the design choice.

In Figure 3 the sign of forces and stresses is conventionally fixed by considering the tension as positive; this assumption is useful for implementing the described procedure in an algorithm for a computer program.

The previous equations have physical meaning only if several geometric and mechanical conditions are fulfilled. For the inclined stress fields of the web, the following inequalities have to be satisfied:

$$
\sigma_{c w} \leq f_{c d 2}
$$

for the compressive stress field and

$$
\begin{aligned}
& \sigma_{l w} \leq f_{s y d}, \\
& \sigma_{t w} \leq f_{s y d}
\end{aligned}
$$

for the tensile stress field in longitudinal and transverse web reinforcements.

For flanges, the following relations must be satisfied:

$$
\begin{aligned}
& -f_{c d 1} \leq \sigma_{f 1} \leq 0 \\
& -f_{c d 1} \leq \sigma_{f 2} \leq 0 .
\end{aligned}
$$

For concrete areas of the web near the flanges the equilibrium conditions can be written as follows:

$$
\begin{aligned}
& -\left(f_{c d 1}+\rho_{l w} \cdot f_{s y d}\right) \leq \sigma_{w 1} \leq \rho_{l w} \cdot f_{s y d} \\
& -\left(f_{c d 1}+\rho_{l w} \cdot f_{s y d}\right) \leq \sigma_{w 2} \leq \rho_{l w} \cdot f_{s y d}
\end{aligned}
$$

where $\rho_{l w}=A_{l w} /\left(b_{w} \cdot h\right)$ is the geometric percentage of reinforcement in the longitudinal direction, $h$ being the web height excluding flanges.

Another condition can be imposed on prestressing tendons, by distinguishing the two following cases: (a) bonded prestressing tendons (complete compatibility between concrete section and prestressing tendon after jacking and duct injection), for which prestressing steel can achieve the yielding stress at the limit state; (b) unbonded prestressing tendon (no compatibility of strains between concrete fibres and prestressing tendon apart from anchorage sections), for which prestressing steel presents only small variations in tensile stresses; in this case the prestressing force being considered constant after prestressing losses is exhausted.

In the first case the prestressing steel presents values of stress limited by the following inequality:

$$
\sigma_{p i} \leq f_{p y d}
$$

while in the second case the prestressing steel maintains the stress level of service life

$$
\sigma_{p i}=\sigma_{p(t \rightarrow \infty) i}
$$

Different expressions have been proposed by researchers $[2,17]$ to evaluate the prestressing steel stress variation from service life to ultimate limit state. Actually all the expressions demonstrate that this variation is very limited; so uncertainties in the determination of stress variation lead to the common assumption of a constant stress, also assumed by the CEB Model Code 90 [33], while Eurocode 2 [34] gives a simplified fixed maximum variation of $100 \mathrm{MPa}$.

Values of layer depths $z_{1}, z_{2}$, and $z_{3}$ can vary inside a prescribed range, due to geometric and mechanical conditions:

$$
z_{1} \geq 0, \quad z_{2} \geq 0, \quad z_{3} \geq z_{3 \min }, \quad z_{1}+z_{2}+z_{3}=h
$$

$z_{3 \text { min }}$ being the minimum value for which the central part of the web can face the shear force acting in the section (mechanical condition). This value can be found by imposing (17) and (19) in (13):

$$
\begin{gathered}
z_{3 \min }=\frac{V_{s d}}{f_{c d 2} \cdot b_{w} \cdot \sqrt{\omega_{t w} \cdot\left(1-\omega_{t w}\right)}} \text { when } \omega_{t w} \leq 0.5 \\
z_{3 \text { min }}=\frac{2 V_{s d}}{f_{c d 2} \cdot b_{w}} \quad \text { when } \omega_{t w}>0.5 .
\end{gathered}
$$

When $h<z_{3 \min }$ it is not possible to proceed with the reinforcement dimensioning because the web is not able to support the entire value of the shear force. This condition corresponds to concrete crush in the web (web-crushing criterion [32]).

\section{3. $M-V$ Interaction Domains}

In engineering practice the use of so-called interaction diagrams or strength domains is very useful and immediate. Moreover, the study of their shapes, even though only qualitative in some cases, supplies important indications in order to make typological choices in the preliminary design.

The use of interaction domains is also a powerful and useful design tool for the final evaluation of the safety level in the ultimate limit state (ULS) and it is helpful for optimization of structural elements.

In this study, with the aim of drawing $M-V$ limit domains, the procedure was implemented for the problem of structural safety verification, even though the same approach could be useful for design problems in which the target is the determination of longitudinal and transverse reinforcements. 


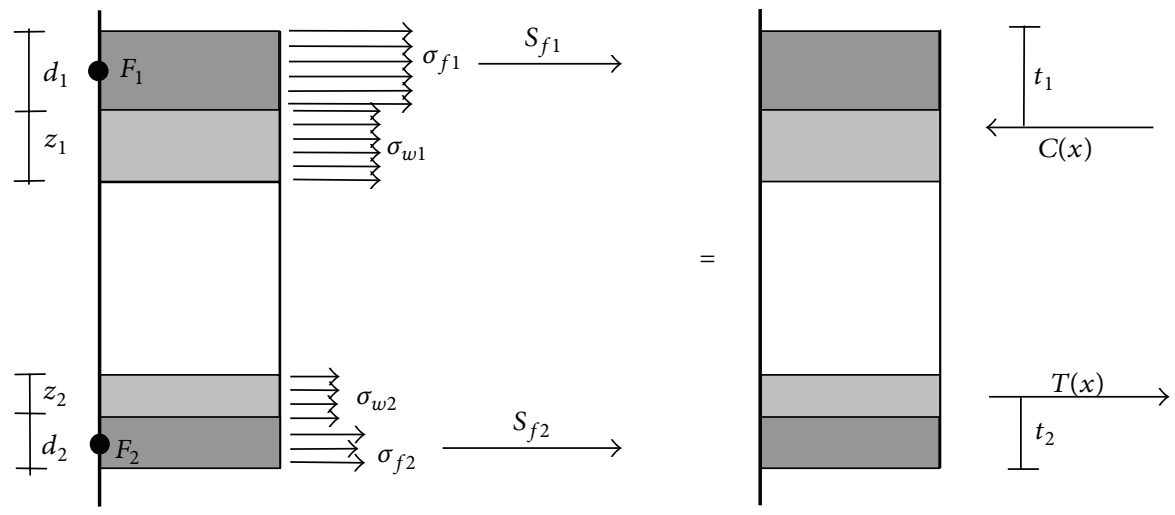

FIGURE 3: Stress equivalence in the beam section. Compressive and tensile stress resultants.

TABLE 1: Geometric properties of the reference samples.

\begin{tabular}{|c|c|c|c|c|c|c|c|c|c|c|}
\hline References & Sample & $\begin{array}{l}f_{\text {cube }} \\
\mathrm{MPa}\end{array}$ & $\begin{array}{c}f_{\text {cyl }} \\
\mathrm{MPa}\end{array}$ & $\begin{array}{c}b_{w} \\
\mathrm{~mm}\end{array}$ & $\begin{array}{c}h \\
\mathrm{~mm} \\
\end{array}$ & $\begin{array}{c}d \\
\mathrm{~mm}\end{array}$ & $\begin{array}{c}d^{\prime} \\
\mathrm{mm}\end{array}$ & $A_{\text {top }}$ & $A_{\text {bottom }}$ & Stirrups \\
\hline \multirow{9}{*}{ [15] } & Beam 1 & 51.50 & 42.75 & 80 & 450 & 415 & 35 & $5 \phi 12$ & $6 \phi 20+2 \phi 16$ & $2 \phi 6 / 100$ \\
\hline & Beam 2 & 41.50 & 34.45 & 80 & 450 & 415 & 35 & $5 \phi 12$ & $6 \phi 20+2 \phi 16$ & $2 \phi 6 / 100$ \\
\hline & Beam 3 & 64.80 & 53.78 & 80 & 450 & 415 & 35 & $5 \phi 12$ & $6 \phi 20+2 \phi 16$ & $2 \phi 6 / 100$ \\
\hline & Beam 4 & 72.10 & 59.84 & 80 & 450 & 415 & 35 & $5 \phi 12$ & $6 \phi 20+2 \phi 16$ & $2 \phi 6 / 175$ \\
\hline & Beam 5 & 31.10 & 25.81 & 80 & 450 & 415 & 35 & $5 \phi 12$ & $6 \phi 20+2 \phi 16$ & $2 \phi 6 / 175$ \\
\hline & Beam 6 & 78.80 & 65.40 & 80 & 450 & 415 & 35 & $5 \phi 12$ & $6 \phi 20+2 \phi 16$ & $2 \phi 6 / 175$ \\
\hline & Beam 7 & 49.20 & 40.84 & 80 & 450 & 415 & 35 & $5 \phi 12$ & $6 \phi 20+2 \phi 16$ & $2 \phi 6 / 70$ \\
\hline & Beam 8 & 33.50 & 27.81 & 80 & 450 & 415 & 35 & $5 \phi 12$ & $6 \phi 20+2 \phi 16$ & $2 \phi 6 / 70$ \\
\hline & Beam 9 & 75.40 & 62.58 & 80 & 450 & 415 & 35 & $5 \phi 12$ & $6 \phi 20+2 \phi 16$ & $2 \phi 6 / 70$ \\
\hline \multirow{8}{*}[16]{} & BQ6 & 34.20 & 28.39 & 59 & 500 & 470 & 30 & $5 \phi 10$ & $10 \phi 16$ & $1 \phi 10 / 48.25$ \\
\hline & BQ7 & 32.80 & 27.22 & 60 & 500 & 470 & 30 & $5 \phi 10$ & $10 \phi 16$ & $1 \phi 10 / 48.25$ \\
\hline & BQ12 & 17.50 & 14.53 & 60 & 500 & 470 & 30 & $5 \phi 10$ & $10 \phi 16$ & $1 \phi 10 / 48.25$ \\
\hline & BQ15 & 39.20 & 32.54 & 60 & 500 & 470 & 30 & $5 \phi 10$ & $10 \phi 16$ & $1 \phi 8 / 61.5$ \\
\hline & BQ16 & 17.90 & 14.86 & 62 & 500 & 470 & 30 & $5 \phi 10$ & $10 \phi 16$ & $1 \phi 6 / 34.5$ \\
\hline & BQ17 & 49.50 & 41.09 & 62 & 500 & 470 & 30 & $5 \phi 10$ & $10 \phi 16+2 \phi 10$ & $1 \phi 6 / 34.5$ \\
\hline & BQ18 & 60.40 & 50.13 & 60 & 500 & 470 & 30 & $5 \phi 10$ & $10 \phi 16+2 \phi 10$ & $1 \phi 6 / 34.5$ \\
\hline & BQ19 & 32.10 & 26.64 & 60 & 500 & 470 & 30 & $5 \phi 10$ & $10 \phi 16$ & $1 \phi 6 / 34.5$ \\
\hline \multirow{7}{*}{ [17] } & ST-1 ${ }^{*}$ & 41.57 & 34.50 & 110 & 300 & 265 & 35 & $4 \phi 8$ & $2 \phi 16$ & $2 \phi 8 / 75$ \\
\hline & ST- $2^{*}$ & 36.02 & 29.90 & 110 & 300 & 265 & 35 & $4 \phi 8$ & $2 \phi 16$ & $2 \phi 8 / 75$ \\
\hline & ST-2C* & 31.57 & 26.20 & 110 & 300 & 265 & 35 & $4 \phi 8$ & $2 \phi 16$ & $2 \phi 8 / 75$ \\
\hline & ST-2C+ ${ }^{*}$ & 22.89 & 19.00 & 110 & 300 & 265 & 35 & $4 \phi 8$ & $2 \phi 20$ & $2 \phi 8 / 75$ \\
\hline & ST-2S* & 37.47 & 31.10 & 110 & 300 & 265 & 35 & $4 \phi 8$ & $2 \phi 16$ & $2 \phi 8 / 200$ \\
\hline & ST-2P* & 43.73 & 36.30 & 110 & 300 & 265 & 35 & $4 \phi 8$ & $2 \phi 16$ & $2 \phi 8 / 75$ \\
\hline & ST $-3^{*}$ & 40.00 & 33.20 & 110 & 300 & 265 & 35 & $4 \phi 8$ & $2 \phi 16$ & $2 \phi 8 / 50$ \\
\hline
\end{tabular}

*Samples externally prestressed with prestressing steel area $A_{p}=261.4 \mathrm{~mm}^{2}$ and strength $f_{\mathrm{pu}}=1900 \mathrm{MPa}$ (see [17]).

With this assumption, let $\rho_{p}$ be the prestressing reinforcement ratio, already defined together with the longitudinal and transverse web reinforcement ratios $\rho_{w l}$ and $\rho_{w t}$. The interaction domains in terms of bending moment and shear force $\left(M_{R d}, V_{R d}\right)$ can be plotted, choosing as the design parameter the flange reinforcement mechanical ratio $\omega_{s}$. The generic $\left(M_{R d}, V_{R d}\right)$ pair can be chosen considering the link $M_{R d}=a V_{R d}, a$ being the shear span of the beam, and changing the value of $a$ within the range $0<\operatorname{arctg} a<90^{\circ}$.
The steps for the determination of the interaction domains are the following

(1) Assign a pair $\left(M_{R d}, V_{R d}\right)$ through a value of $V_{R d}$, and compute the minimum web depth $z_{3 \text { min }}$ by (25); if $z_{3 \min }>h$, then it is not possible to proceed, because the web is not able to face the shear stresses and in this case a lower value of $V_{R d}$ has to be considered. 
(2) Assign trial values of $z_{1}, z_{2}$, and $z_{3}$, respecting conditions (24).

(3) Choose the pair of arms $t_{1}$ and $t_{2}$; the values of the additional flange reinforcements, $A_{f 1}$ and $A_{f 2}$, and the ratio $r$ between them are calculated through (15), (16).

(4) Evaluate the longitudinal top and bottom flange reinforcement ratio $r$ and the subsequent values of $A_{f 1}$ and $A_{f 2}$; if necessary, increase them to fulfill other requirements (e.g., to obtain a given ratio of the longitudinal reinforcements of the top and bottom flange).

(5) Compute the total longitudinal flange reinforcement mechanical ratio $\omega_{s}$.

(6) Repeat steps (2) to (5), in order to minimize the total flange reinforcements, thus obtaining the value of $\omega_{s}$ corresponding to the chosen pair $\left(M_{R d}, V_{R d}\right)$.

(7) If the value $\omega_{s}$ does not correspond to the target value, a different pair $\left(M_{R d}, V_{R d}\right)$ can be chosen and the entire procedure is repeated from step (1), till the whole $M_{R d}-V_{R d}$ interaction domain is obtained with a fixed value of parameter $\omega_{s}$.

The procedure here illustrated has to be managed according to nonlinear programming procedures, allowing one to obtain the strength domains of the cross-section, for given web and flange reinforcements. The characteristics to be introduced in the domains are the following:

(i) transverse web reinforcement mechanical ratio and longitudinal web reinforcement ratio

$$
\omega_{t w}=\frac{A_{t w}}{b_{w} \cdot s} \cdot \frac{f_{s y d}}{f_{c d 2}}, \quad \omega_{l w}=\frac{A_{l}}{b_{w} \cdot h} \cdot \frac{f_{s y d}}{f_{c d 2}} ;
$$

(ii) total longitudinal flange reinforcement mechanical ratio

$$
\omega_{s}=\frac{A_{f 1}+A_{f 2}}{A_{c}} \cdot \frac{f_{s y d}}{f_{c d 1}},
$$

where $A_{c}$ is the total concrete area of cross-section;

(iii) prestressing steel mechanical ratio

$$
\omega_{p}=\frac{\sum A_{p i}}{A_{c}} \cdot \frac{f_{p y d}}{f_{c d 1}} ;
$$

(iv) dimensionless bending moment and shear force

$$
\begin{gathered}
m=\frac{M}{f_{c d 1} \cdot A_{c} \cdot H}, \\
v=\frac{V}{f_{c d 2} \cdot b_{w} \cdot h},
\end{gathered}
$$

where $H$ is the total height of the cross-section;

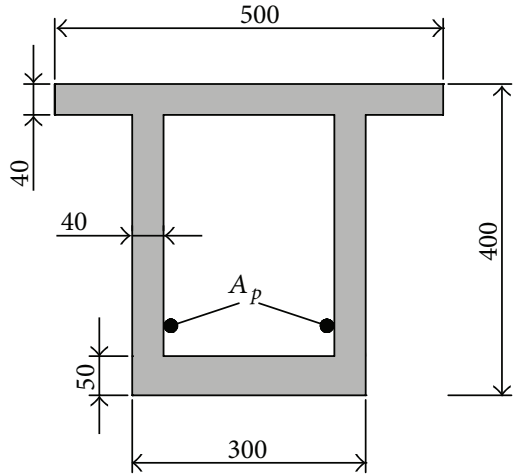

FIGURE 4: Geometric properties of the box section used in the numerical example $[\mathrm{cm}]$.

(v) flange reinforcement ratio

$$
r=\frac{A_{f 1}}{A_{f 2}}
$$

(vi) design yield strength of unprestressed and prestressed reinforcement $f_{\text {syd }}, f_{\text {pyd }}$;

(vii) design strength of the concrete for axial load and transverse load $(\mathrm{MPa})$

$$
\begin{aligned}
& f_{c d 1}=0.85 \cdot\left(1-\frac{f_{c k}}{250}\right) \cdot \frac{f_{c k}}{\gamma_{c}}, \\
& f_{c d 2}=0.60 \cdot\left(1-\frac{f_{c k}}{250}\right) \cdot \frac{f_{c k}}{\gamma_{c}}
\end{aligned}
$$

with $\gamma_{c}$ partial the safety factor of the concrete.

A numerical example on the box cross-section of a prestressed railway girder bridge is shown (Figure 4) and the related interaction domains are found by the previous procedure.

The value of the concrete compressive strength is $f_{c k}=$ $45 \mathrm{MPa}$ with $\gamma_{c}=1.5$, and the design yield strength of the prestressing steel is $f_{\text {pyd }}=1670 \mathrm{MPa}$ with a permanent stress at the infinite time (service life value of prestressing); after prestressing losses are exhausted, $\sigma_{p \infty}=900 \mathrm{MPa}$.

According to design practice, the following parameters were assumed: $\omega_{p}=0.30, \omega_{t w}=0.3,0.4,0.5$, and $\operatorname{tg} \varepsilon=$ $0.00,0.10$. Finally, the numerical example presented being on a precast segmental structure with dry joints between segments, the mechanical ratio of the longitudinal reinforcement passing between the segments were assumed with null values $\omega_{s}=0.0$ and $\omega_{l w}=0.0$.

Domains were plotted in two cases:

(a) bonded prestressing tendons with perfect adherence with the concrete fibres of the cross-section;

(b) unbonded prestressing tendons, totally placed outside the concrete cross-section.

The diagrams in Figure 5 show that the interaction between the shear force $V$ and the bending moment $M$ cannot 

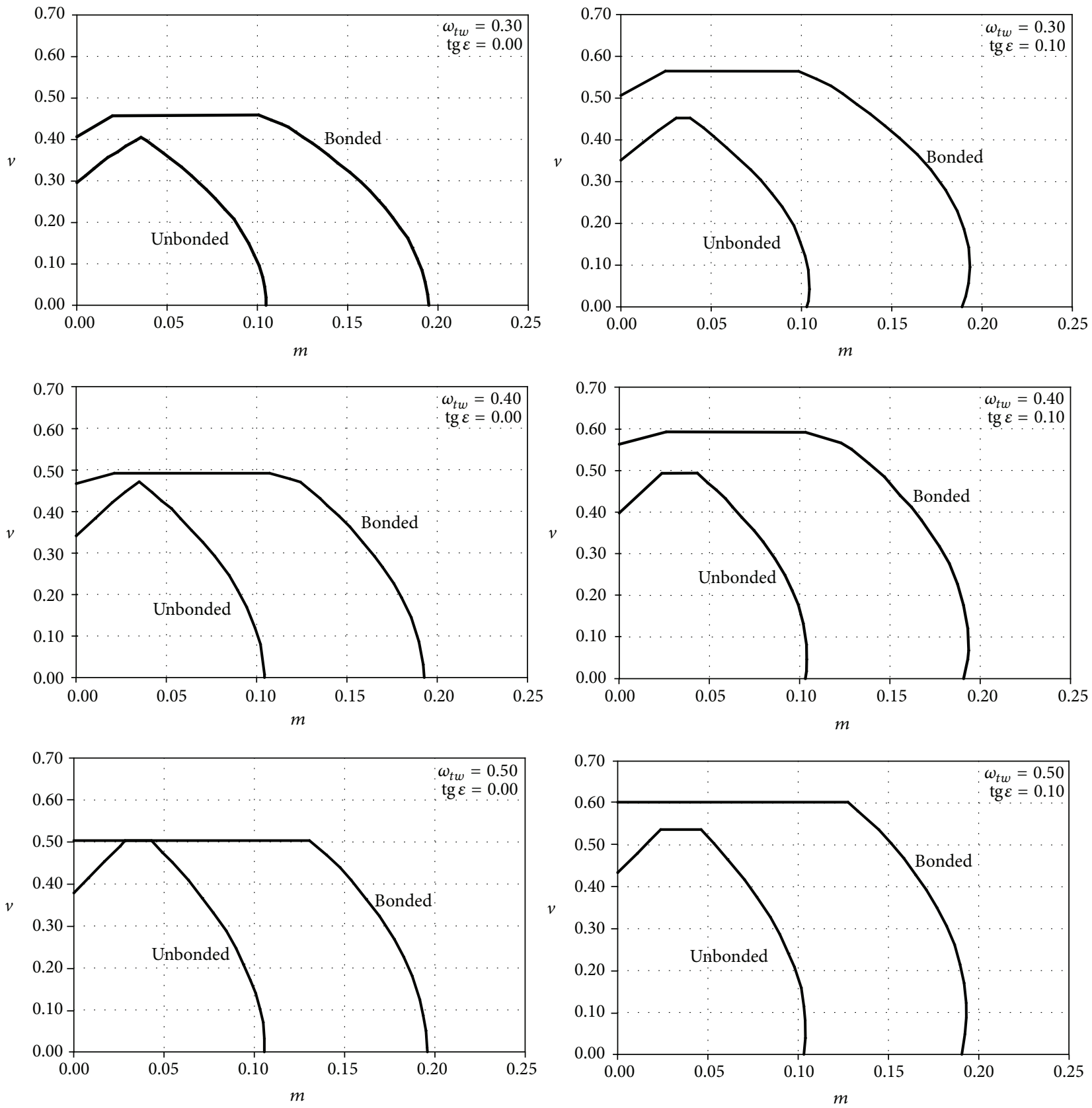

FIGURE 5: $M-V$ interaction domains for different values of reinforcement ratios and prestressing tendon slope.

be neglected in prestressed structures. With an increasing variation in bending moment a corresponding decrease in the limit shear value occurs, and with an increasing variation in shear, the moment strength decreases. Moreover, the healthful effect of the tendon slope, that makes it possible to face a high value of shear force, is evident, as demonstrated by experimental evidence. Indeed, diagrams with $\operatorname{tg} \varepsilon=0.10$ show wider areas of domains. In both cases a larger mechanical transverse web reinforcement ratio influences the bending and shear capacity corresponding to an improvement of the structure performance with higher values of $\omega_{t w}$, even though a greater influence of $\omega_{t w}$ is shown by unbonded prestressing.
From Figure 5 the strength reduction in the case of unbonded prestressing tendons, with respect to the bonded ones, can be noted. In all domains the strength of unbonded tendons is about half, in terms of bending moments, with respect to bonded prestressing. Moreover, the diagrams of the unbonded tendons are lower than the bonded ones and less flat: this demonstrates that the capacity in terms of shear is also strongly reduced.

The plateau of each diagram corresponds to web concrete crushing and the section never has greater strength. With an increasing variation in the tendon slope, web crushing can be achieved for unbonded prestressing, while for tg $\varepsilon=0$ 
the plateau cannot be reached and the domain presents a vertex. For the maximum value of the transverse reinforcement $\left(\omega_{t w}=0.5\right)$ and horizontal tendons, unbonded and bonded prestressing can achieve the same value of shear strength for web crushing, while in all other cases the value of unbonded prestressing is lower than the bonded one. Moreover, for horizontal cables, the maximum value of bending strength is achieved without shear $(v=0)$, while for inclined tendons, the maximum value of bending is combined with a finite shear value $(v>0)$. For the section investigated the maximum capacity is achieved with the maximum value of transverse reinforcement and an inclined tendon for bonded prestressing $\left(\omega_{t w}=0.5, \operatorname{tg} \varepsilon=0.10\right)$. Naturally, all outcomes are strictly related to the cross-section case examined. By plotting interaction domains for different sections the designer can evaluate the reduction in strength due to the unbonded prestressing and the influence of shear on beam failure.

\section{Experimental Comparison and Validation}

The reliability of the proposed model is validated by comparing its numerical results to the strength values obtained by means of failure tests reported in the literature.

In particular, seven tests on unbonded prestressed beams and seventeen on simple reinforced beams were found.

The first ones are reported by Tan and $\mathrm{Ng}$ [17] on externally prestressed concrete beams with T-shaped crosssections; nine other values are part of tests carried out by Robinson and Demorieux [16]; finally, eight values are obtained through the experimental work of Regan and RezaiJorabi [15].

Samples of tests presented by these authors were designed to fail in shear by crushing of web concrete, after stirrup yielding. Further details may be found in the original papers.

The comparison was made by evaluating the ultimate load force values $\left(F_{\text {cal }}\right)$, as the ultimate capacity of each sample calculated through the analytical model. The results are reported in the diagrams as points of coordinates $\left(F_{\text {test }}, F_{\text {cal }}\right)$ and compared to the straight line at $45^{\circ}$, which represents the theoretical case of test strength equal to the calculated one. In numerical analyses, the uniaxial strength $f_{c d 1}$ was evaluated neglecting the long-time reduction factor $\alpha_{c c}=0.85$ and assuming the partial safety factor $\gamma_{c}=1$.

Table 1 shows the geometric properties of the specimens used in the reference studies, while Table 2 gives the values of the ratio $F_{\text {cal }} / F_{\text {test }}$ for all the samples.

In T-shaped beams, for generation of the model, flange reinforcement was concentrated at its centre. For calibration of the tension chord depth, two hypotheses were made:

(i) the depth is equal to the web height excluding the flanges $\left(A_{1}\right.$ and $\left.B_{1}\right)$;

(ii) the depth is equal to the distance from the top flange to the physical dimension of ordinary steel in the bottom flange, which is a greater depth than in the previous case $\left(A_{2}\right.$ and $\left.B_{2}\right)$.
TABLE 2: Values of ratio $F_{\text {cal }} / F_{\text {test }}$ for the reference samples.

\begin{tabular}{|c|c|c|c|c|c|}
\hline References & Sample & $A_{1}$ & $A_{2}$ & $B_{1}$ & $B_{2}$ \\
\hline \multirow{9}{*}[15]{} & Beam 1 & 0.840 & 0.935 & 0.695 & 0.775 \\
\hline & Beam 2 & 0.835 & 0.930 & 0.685 & 0.765 \\
\hline & Beam 3 & 0.745 & 0.830 & 0.620 & 0.690 \\
\hline & Beam 4 & 0.665 & 0.750 & 0.600 & 0.665 \\
\hline & Beam 5 & 0.785 & 0.870 & 0.650 & 0.720 \\
\hline & Beam 6 & 0.705 & 0.795 & 0.655 & 0.730 \\
\hline & Beam 7 & 0.880 & 0.980 & 0.720 & 0.800 \\
\hline & Beam 8 & 1.045 & 1.165 & 0.845 & 0.940 \\
\hline & Beam 9 & 0.785 & 0.790 & 0.650 & 0.725 \\
\hline \multirow{8}{*}[16]{} & BQ6 & 0.980 & 1.145 & 0.695 & 0.810 \\
\hline & BQ7 & 0.965 & 1.125 & 0.680 & 0.795 \\
\hline & BQ12 & 0.725 & 0.845 & 0.605 & 0.605 \\
\hline & BQ15 & 1.020 & 1.190 & 0.720 & 0.850 \\
\hline & BQ16 & 0.730 & 0.850 & 0.605 & 0.605 \\
\hline & BQ17 & 0.775 & 0.870 & 0.605 & 0.680 \\
\hline & BQ18 & 0.695 & 0.800 & 0.615 & 0.715 \\
\hline & BQ19 & 0.945 & 1.105 & 0.665 & 0.780 \\
\hline \multirow{9}{*}{ [17] } & ST-1 & 0.800 & 0.810 & 0.800 & 0.810 \\
\hline & ST-2 & 0.845 & 0.855 & 0.845 & 0.855 \\
\hline & ST-2C & 0.855 & 0.860 & 0.855 & 0.860 \\
\hline & ST-2C+ & 1.055 & 1.060 & 0.845 & 1.010 \\
\hline & ST-2S & 0.655 & 0.670 & 0.655 & 0.670 \\
\hline & ST-2P & 0.765 & 0.770 & 0.765 & 0.770 \\
\hline & ST-3 & 0.930 & 0.930 & 0.930 & 0.930 \\
\hline & Mean & 0.834 & 0.914 & 0.709 & 0.773 \\
\hline & Variance & 0.120 & 0.145 & 0.097 & 0.102 \\
\hline
\end{tabular}

In cases $A_{1}$ and $A_{2}$ the web concrete strength was assumed equal to $f_{c d 1}$ as the concrete strength of the flange, while in cases $B_{1}$ and $B_{2}$ a reduced strength $f_{c d 2}$ of the stress fields was assumed.

Analysis of the experimental results shows that the model reproduces the actual behaviour near failure accurately, and it is very sensitive to the reduction in the web concrete strength and to the reduction in the web height $(h)$, which is strictly related to the strength in terms of shear forces (Figure 6). It is also evident that in cases $B_{1}$ and $B_{2}$, for which a reduced strength of the concrete stress field is assumed, the values found through the analytical model present a "lower bound solution" consistently with the hypotheses on which it was constructed.

It is worth noting that case $A_{2}$ (related to the maximum web height and without reduction in concrete strength) shows the highest values with some specimens placed above the 45 degree line. By contrast, case $B_{1}$ (related to the web height excluding flanges and to the reduced concrete strength) shows the lowest values with higher variance with respect to the theoretical value. The latter condition clearly underestimates the beam strength, while condition $A_{2}$ could overestimate it. 

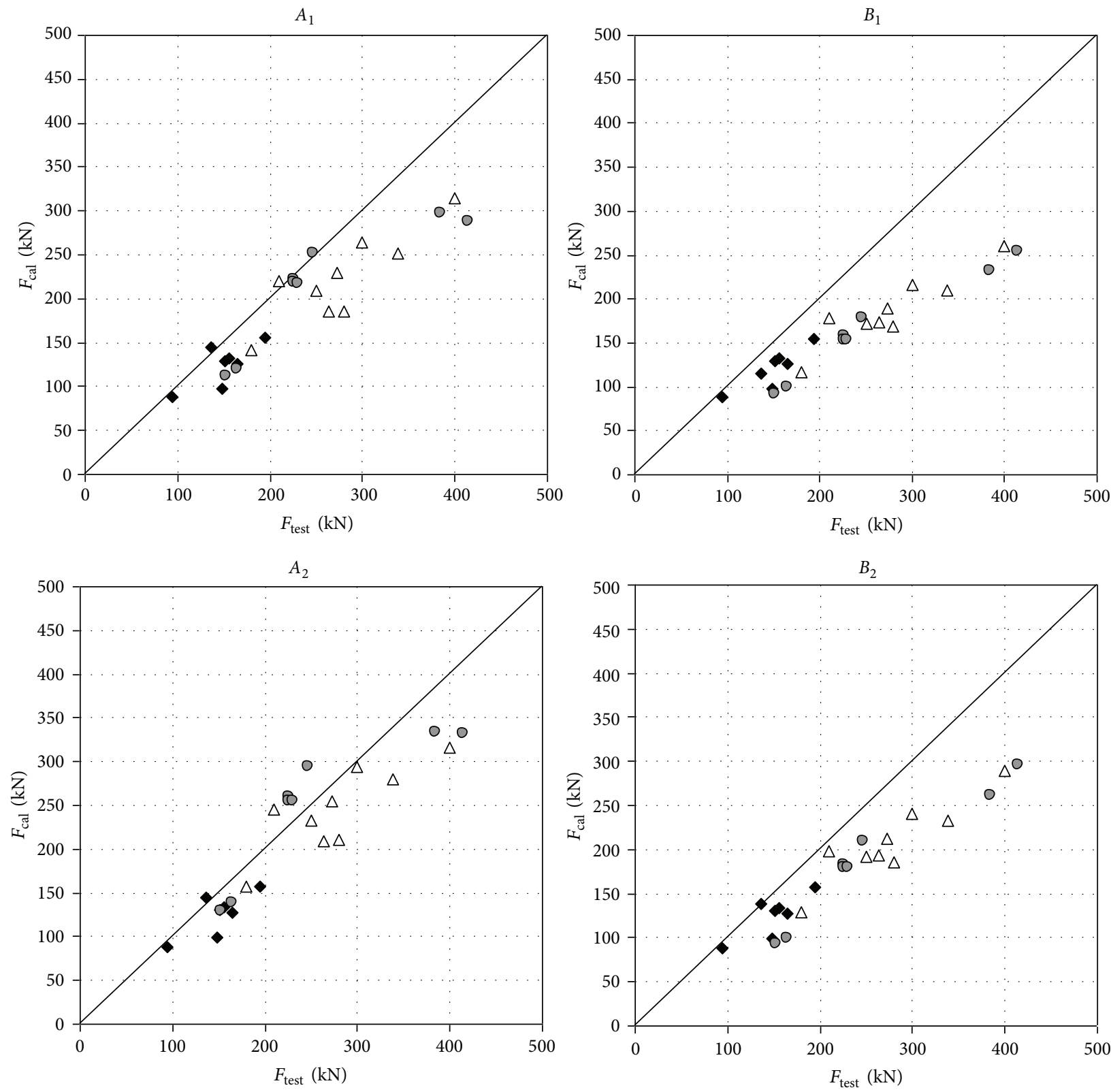

- Ref. [29]

- Ref. [29]

$\triangle$ Ref. [30]

$\triangle$ Ref. [30]

O Ref. [31]

○ Ref. [31]

FIGURE 6: Comparison with experimental data in the four cases examined.

\section{Concluding Remarks}

An analytical model for the study of bending-shear interaction in prestressed concrete girders has been proposed in the present paper for structural elements with T-, I-shaped or box cross-sections. The differences between bonded and unbonded prestressed elements have been underlined.

Strength domains render evidently a very strong interaction between bending moment and shear in the case of both bonded and unbonded prestressing. In all domains the strength of unbonded tendons is about half, in terms of bending moments, with respect to bonded prestressing. Moreover, the diagrams of unbonded tendons are lower than bonded ones and less flat: this demonstrates that the capacity in terms of shear is strongly reduced. With an increasing variation in bending moment a corresponding decrease in limit shear value occurs, and with an increasing variation in shear, moment strength decreases.

Moreover the proposed model allows designers to estimate the reduction in strength in terms of shear and bending moments for structures with unbonded tendons, with variation in the amount of stirrups and tendon slope. For 
the maximum value of transverse reinforcement and horizontal tendons, unbonded and bonded prestressing can achieve the same value of shear strength for web crushing, while in all other cases the value of unbonded prestressing is lower than the bonded one.

For horizontal cables, the maximum value of bending strength is achieved without shear $(v=0)$, while for inclined tendons, the maximum value of bending is combined with a finite shear value $(v>0)$ : this demonstrates the contribution of tendon slope to shear strength.

The comparison between the proposed model and results of experimental tests found in the literature shows that the analytical model is consistent with experimental results. These results are in agreement with those found in previous studies concerning structures with ordinary unprestressed reinforcements. Values found through the analytical model present a "lower bound solution," consistently with the hypotheses on which it was constructed. The diagrams show that the proposed model is very sensitive to the reduction in web concrete strength and to the reduction in web height, which is strictly related to the strength in terms of shear forces.

Finally, the use of interaction domains is encouraged as a convenient graphic design-verification tool, able to show the interaction effects between internal forces.

\section{Notation}

\begin{tabular}{|c|c|}
\hline$\alpha:$ & Inclination of the uniform web stress field \\
\hline 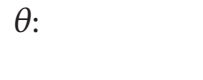 & $\begin{array}{l}\text { Inclination of the stress field related to } \\
\text { transverse reinforcement }\end{array}$ \\
\hline$c w:$ & Stress field related to concrete web \\
\hline$T_{t w}:$ & $\begin{array}{l}\text { Stress field related to transverse } \\
\text { reinforcement }\end{array}$ \\
\hline$\tau_{l w}:$ & $\begin{array}{l}\text { Stress field related to longitudinal } \\
\text { reinforcement }\end{array}$ \\
\hline$\omega_{l w}:$ & $\begin{array}{l}\text { Longitudinal web reinforcement } \\
\text { mechanical ratio }\end{array}$ \\
\hline$\omega_{t w}:$ & $\begin{array}{l}\text { Transverse web reinforcement mechanical } \\
\text { ratio }\end{array}$ \\
\hline$\omega_{p}:$ & Prestressing steel mechanical ratio \\
\hline$\omega_{s}:$ & $\begin{array}{l}\text { Total longitudinal flange reinforcement } \\
\text { mechanical ratio }\end{array}$ \\
\hline .0 & Shear span of the beam \\
\hline$A_{p i}, \sigma_{p i}, \varepsilon_{i}:$ & $\begin{array}{l}\text { Farea, axial stress and slope of the } i \text { th } \\
\text { prestressing tendon }\end{array}$ \\
\hline$A_{\text {top }}, A_{\text {bottom }}$ & $\begin{array}{l}\text { Areas of top and bottom reinforcement } \\
\text { bars }\end{array}$ \\
\hline & Web thickness \\
\hline$T:$ & $\begin{array}{l}\text { Compressive and tensile resultants of } \\
\text { cross-section }\end{array}$ \\
\hline$d, d^{\prime}:$ & $\begin{array}{l}\text { Height of cross-section referred to steel in } \\
\text { tension, concrete cover depth }\end{array}$ \\
\hline & $\begin{array}{l}\text { Strength of ordinary steel of } \\
\text { reinforcements }\end{array}$ \\
\hline & Strength of prestressing steel \\
\hline & Compressive strength of concrete \\
\hline
\end{tabular}

$f_{c d 2}: \quad$ Reduced compressive strength of concrete for transverse loads

$f_{\text {cube }}, f_{\text {cyl }}$ : Cubic and cylinder compressive strength of sample concrete

$h$ : $\quad$ Height of cross-section

$m, v$ : Dimensionless bending moment and shear force

$M_{R d}, V_{R d}$ : Limit values of bending moment and shear

$M_{s d}, V_{s d}$ : Design values of bending moment and shear

$r$ : $\quad$ Flange reinforcement ratio

$t_{1}, t_{2}$ : Top and bottom flange depths

$S_{f 1}, S_{f 2}$ : Axial forces in top and bottom reinforcements

$x: \quad$ Generic beam section

$\bar{z}_{1}$ : $\quad$ Distance from the point of application of compressive force to the lowest compression fibre

$\bar{z}_{2}$ : $\quad$ Distance from the point of application of tensile force to the highest tension fibre

$z_{3}$ : $\quad$ Depth of web sheer-resistant area.

\section{References}

[1] F. T. K. Au and J. S. Du, "Prediction of ultimate stress in unbonded prestressed tendons," Magazine of Concrete Research, vol. 56, no. 1, pp. 1-11, 2004.

[2] A. E. Naaman, N. Burns, C. French, W. L. Gamble, and A. H. Mattock, "Stresses in unbonded prestressing tendons at ultimate: recommendation," ACI Structural Journal, vol. 99, no. 4, pp. 518-529, 2002.

[3] M. Moravcik and I. Dreveny, "Strengthening and verification of the prestressed road bridge using external prestressing," in Concrete Repair, Rehabilitation and Retrofitting II, M. G. Alexander, H.-D. Beushausen, F. Dehn, and P. Moyo, Eds., pp. 1077-1080, Taylor \& Francis, London, UK, 2009.

[4] G. Fanti and G. Mancini, "Shear-prestressing interaction in ultimate limit state design," in Developments in Short and Medium Span Bridge Engineering, Halifax, UK, 1994.

[5] P. P. Rossi and A. Recupero, "Ultimate strength of reinforced concrete circular members subjected to axial force, bending moment and shear force," Journal of Structural Engineering ASCE, vol. 139, no. 6, pp. 915-928, 2013.

[6] A. Recupero, A. D’Aveni, and A. Ghersi, "Bending momentshear force interaction domains for prestressed concrete beams," Journal of Structural Engineering, vol. 131, no. 9, pp. 1413-1421, 2005.

[7] J. M. Bairan Garcia and A. R. Mari Bernat, "Coupled model for the non-linear analysis of anisotropic sections subjected to general 3D loading. Part 1: theoretical formulation," Computers and Structures, vol. 84, no. 31-32, pp. 2254-2263, 2006.

[8] J. M. Bairan Garcia and A. R. Mari, "Coupled model for the nonlinear analysis of sections made of anisotropic materials, subjected to general 3D loading. Part 2: implementation and validation," Computers and Structures, vol. 84, no. 31-32, pp. 2264-2276, 2006.

[9] J. M. Bairan Garcia and A. R. Mari Bernat, "Shear-bendingtorsion interaction in structural concrete members: a nonlinear coupled sectional approach," Archives of Computational Methods in Engineering, vol. 14, no. 3, pp. 249-278, 2007. 
[10] K. N. Rahal, "Combined torsion and bending in reinforced and prestressed concrete beams using simplified method for combined stress-resultants," ACI Structural Journal, vol. 104, no. 4, pp. 402-411, 2007.

[11] G. Bertagnoli and G. Mancini, "Failure analysis of hollow-core slabs tested in shear," Structural Concrete, vol. 10, no. 3, pp. 139$152,2009$.

[12] G. Russo, G. Zingone, and G. Puleri, "Flexure-shear interaction model for longitudinally reinforced beams," ACI Structural Journal, vol. 88, no. 1, pp. 60-68, 1991.

[13] G. Russo and G. Puleri, "Stirrup effectiveness in reinforced concrete beams under flexure and shear," ACI Structural Journal, vol. 94, no. 3, pp. 227-238, 1997.

[14] A. Recupero, A. D'Aveni, and A. Ghersi, "N-M-V interaction domains for box and I-shaped reinforced concrete members," ACI Structural Journal, vol. 100, no. 1, pp. 113-119, 2003.

[15] P. E. Regan and H. Rezai-Jorabi, "The Shear resistance of reinforced concrete I-beams," in Studi e Ricerche, Politecnico di Milano, vol. 9, pp. 305-321, Milan, Italy, 1987.

[16] J. R. Robinson and J. M. Demorieux, "Essais de Poutres en double té en Béton Armé," Annales de l'Institut Technique du Bâtiment et des Travaux Publics, vol. 153, pp. 66-91, 1976.

[17] K.-H. Tan and C.-K. Ng, "Effect of shear in externally prestressed beams," ACI Structural Journal, vol. 95, no. 2, pp. 116128, 1998.

[18] M. W. Braestrup, M. P. Nielsen, and F. Bach, "Rational analysis of Shear in reinforced concrete beams," in Proceedings of the International Association for Bridge and Structural Engineering (IABSE '78), 1978.

[19] "Fib, Bulletin d'Information 65-Model Code 2010-Final draft, Volumes 1 and 2, fib, Lausanne, Switzerland, 2012".

[20] ACI, "ACI 445R-99 Recent Approaches to Shear Design of Structural Concrete," Reported by Joint ACI-ASCE Committee 445. Manual of concrete practice, pp. 1-55, 1999.

[21] P. Colajanni, A. Recupero, and N. Spinella, "Generalization of shear truss model to the case of SFRC beams with stirrups," Computers \& Concrete, vol. 9, no. 3, pp. 227-244, 2012.

[22] N. Spinella, P. Colajanni, and A. Recupero, "Simple plastic model for shear critical SFRC beams," Journal of Structural Engineering, vol. 136, no. 4, pp. 390-400, 2010.

[23] G. Bertagnoli, G. Mancini, A. Recupero, and N. Spinella, "Rotating compression field model for reinforced concrete beams under prevalent shear actions," Structural Concrete, vol. 12, no. 3, pp. 178-186, 2011.

[24] G. Bertagnoli and V. I. Carbone, "A finite element formulation for concrete structures in plane stress," Structural Concrete, vol. 9, no. 2, pp. 87-99, 2008.

[25] A. Perez and H. Corres, "Influence of construction sequence in prestressed concrete bridges," in Proceedings of the 5th International RILEM Symposium on Creep and Shrinkage of Concrete, Barcelona, Spain, 1993.

[26] M. F. Granata and M. Arici, "Serviceability of segmental concrete arch-frame bridges built by cantilevering," Bridge Structures, vol. 9, no. 1, pp. 21-36, 2013.

[27] M. Arici and M. F. Granata, "Analysis of curved incrementally launched box concrete bridges using Transfer Matrix Method," Bridge Structures, vol. 3, no. 3-4, pp. 165-181, 2007.

[28] M. F. Granata, P. Margiotta, and M. Arici, "A parametric study of curved incrementally launched bridges," Engineering Structures, vol. 49, pp. 373-384, 2013.
[29] M. F. Granata, P. Margiotta, and M. Arici, "A simplified procedure for evaluating the effects of creep and shrinkage on prestressed concrete girder bridges and the application of European and North American prediction models," Journal of Bridge Engineering ASCE, vol. 18, no. 12, pp. 1281-1297, 2013.

[30] M. F. Granata, P. Margiotta, A. Recupero, and M. Arici, "Partial elastic scheme method in cantilever construction of concrete arch bridges," Journal of Bridge Engineering ASCE, vol. 18, no. 7, pp. 663-672, 2013.

[31] M. F. Granata, P. Margiotta, A. Recupero, and M. Arici, "Concrete arch bridges built by lattice cantilevers," Structural Engineering and Mechanics, vol. 45, no. 5, pp. 703-722, 2013.

[32] M. W. Braestrup, "Structural concrete beam Shear-still a riddle?” ACI Special Publication, vol. 15, pp. 327-344, 2009.

[33] CEB, Bulletin d'Information no 213/214-CEB-FIP Model code 1990, Thomas Telford, London, UK, 1993.

[34] CEN, EN 1992-1-1 Eurocode 2-Design of Concrete StructuresPart 1.1: General Rules and Rules for Buildings, 2005. 

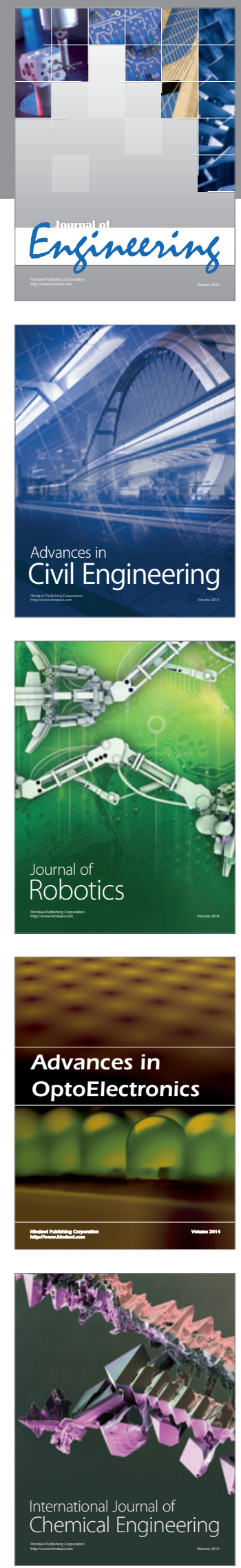

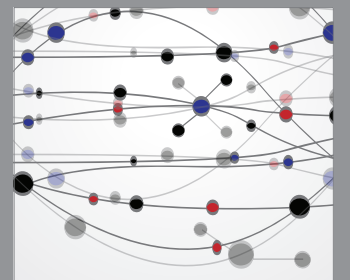

The Scientific World Journal
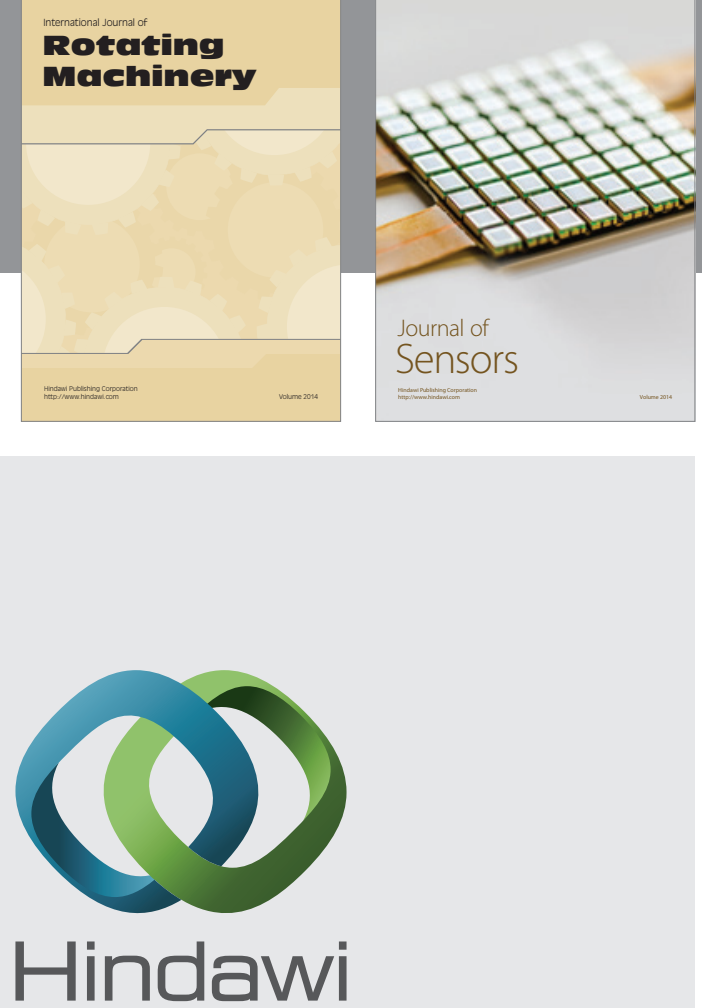

Submit your manuscripts at http://www.hindawi.com
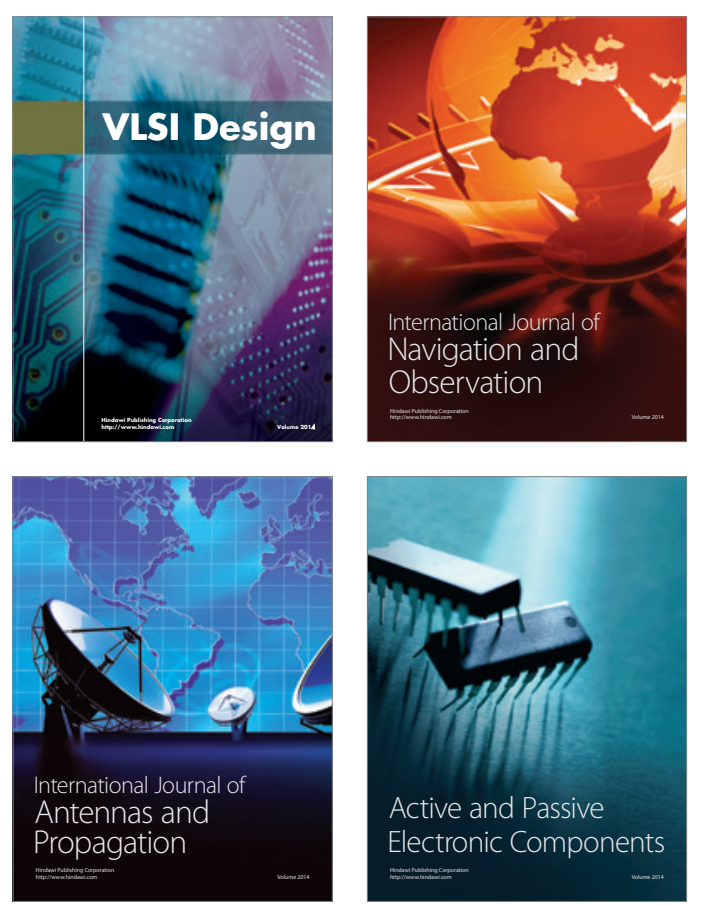
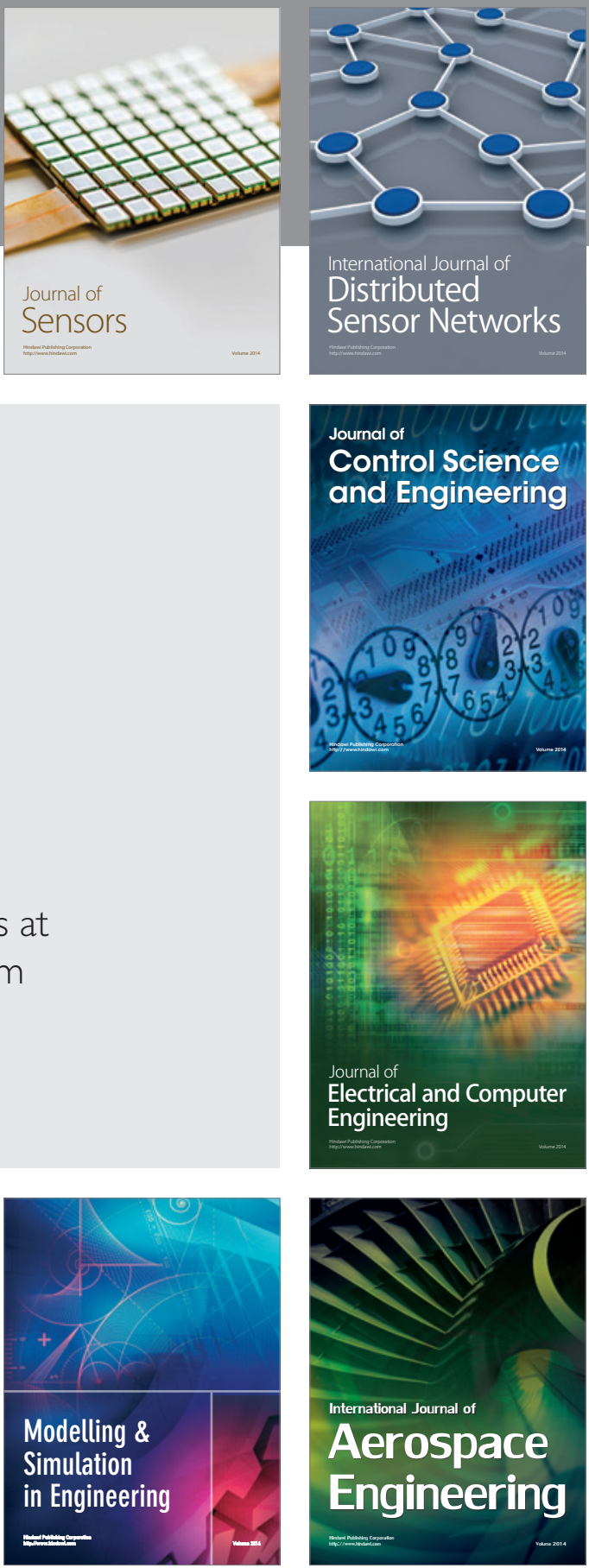

Journal of

Control Science

and Engineering
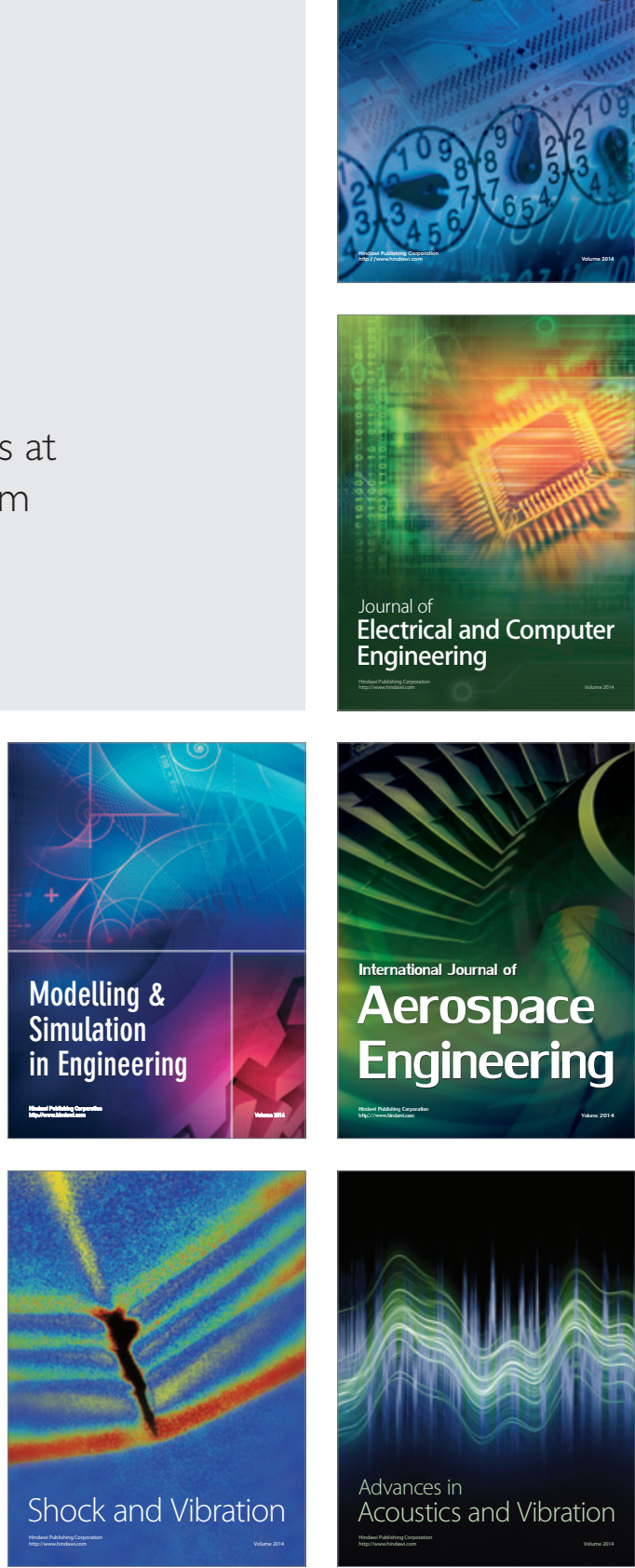